\title{
Development of a novel TIG hot-wire process for wire and arc additive manufacturing
}

\author{
E. Spaniol ${ }^{1} \cdot$ T. Ungethüm ${ }^{1} \cdot$ M. Trautmann ${ }^{1} \cdot$ K. Andrusch ${ }^{1} \cdot$ M. Hertel $^{1} \cdot$ U. Füssel $^{1}$
}

Received: 15 May 2019 / Accepted: 17 February 2020 / Published online: 10 March 2020

(C) The Author(s) 2020

\begin{abstract}
The presented work deals with the development of a novel TIG hot-wire process for the additive manufacturing of metallic components, which, in contrast to previous arc processes, enables a significant increase in melting performance with simultaneously reduced heat input. This is achieved by means of an upstream resistance heating of the wire between two contact points within the hot wire feeding system. The torch, hot wire feeder and gas nozzle are designed in such a way that a constant bead geometry can be guaranteed regardless of the machining direction. On the one hand, this can improve the dimensional accuracy; on the other hand, an increase in productivity is achieved through a significant reduction of process times. Essential parts of the work include the simulation-supported development of the processing system, the design and implementation of an innovative process control system and the testing of the new technology.
\end{abstract}

Keywords WAAM $\cdot$ GTAW $\cdot$ TIG $\cdot$ Hotwire $\cdot$ SPH

\section{Introduction}

The increasing digitalization of industrial value chains requires the development of new, intelligent manufacturing technologies that are not only characterised by a high degree of automation but are also capable of producing a wide range of complex component geometries in small quantities at low production costs. The demands for highly flexible, competitive small-series production can not be met sufficiently to a limited extent by conventional primary shaping, forming and cutting production processes, so that the development of additive production technologies is focused. They represent a complementary technology to existing, conventional processes and offer the user completely new possibilities with regard to geometric design. Additive manufacturing technologies are based on the use of a $\mathrm{CAD} / \mathrm{CAM}$ environment that enables computer-aided component modelling and design to be increasingly networked

This article is part of the collection Additive Manufacturing - Processes, Simulation and Inspection Recommended for publication by Commission XII - Arc Welding Processes and Production Systems

E. Spaniol

erik.spaniol@tu-dresden.de

1 Technische Universität Dresden, 01069 Dresden, Germany with component production. The layered production of parts and components, using additive manufacturing technologies, allows the realisation of resource-efficient, sustainable production through the consistent utilisation of the function-integrated lightweight construction potential (e.g. internal cooling channels, multi-material design) [1]. At the present, the majority of additive manufacturing technologies are based on the use of a wire or powdered filler material that is melted by laser, electron beam or arc processes [2-4], whereby the energy source is moved over the substrate by a robot or a CNC system according to the specified component geometry [5]. While beambased additive manufacturing processes are particularly suitable for the production of highly complex components with small sizes [3, 4], arc-based processes are primarily suitable for the production of large-volume components with moderate complexity $[2,6]$. The melting rates of arc processes exceed those of beam-based processes by many times, so that a very high productivity can be achieved. At the same time, the investment, operating and maintenance costs of arc processes are only a fraction of those of beam-based processes, being the reason why arc-based processes are particularly suitable for applications in small and medium-sized companies [2]. Despite the numerous advantages, additive arc processes are not widespread in mass production so far, since the requirements for geometric dimensional accuracy and material properties (prevention of Widmannstätten structure) cannot be 
sufficiently met [7]. The reason for this is the high local heat input that is typical for welding processes. On one hand, this leads to a change in the microstructure. On the other hand, there is a locally uneven expansion and contraction of the metallic material. As a result thermally induced stresses are introduced into the component during the production process $[8,9]$. These internal stresses cause distortion, so that the desired dimensional tolerances cannot be achieved. Martina et al. $[10,11]$ show the integration of mechanical rollers as a possible way for compensating residual stresses and distortion.

The limitation of the introduced heat and thus the influencing of the component properties using arc processes for additive manufacturing can be realised in different ways. Depending on the arc type, GMAW processes introduce relatively much heat into the workpiece due to the coupling of energy and filler material supply. At the same time, the filler material is fed coaxially and is therefore evenly molten through the arc. To limit heat input and thus the penetration, GMAW processes with modified short arcs (e.g. ColdArc or CMT) are mainly used in additive production [12-17]. However, the resulting process-related melting rates are limited. In contrast, GMAW welding processes with pulsed, spray or rotating arc have high melting rates [18], but the higher local heating of the components has a pronounced influence on the microstructure as well as the formation of residual stresses and distortion. This often means that the mechanic and geometric requirements cannot be met [19]. The resulting long cooling times between the individual layers, which must be observed in order to prevent the components from collapsing due to excessive heating, also lead to a significant reduction of economic efficiency caused by very long process times [20].

Compared to GMAW processes, GTAW hot wire processes are characterised by a separate supply of energy and filler material. Therefore, it is possible to control the heat input better [21]. This makes it possible to ignite the arc independently of the filler material supply by means of highfrequency or drawn arc ignition, which facilitates a stable, spatter-free starting process. TIG hot wire processes are mainly used in the additive production of highly reactive materials such as high-alloyed steels as well as titanium and nickelbased alloys [22-30]. However, a striking disadvantage of processes with a non-melting electrode is that the torch is set vertically with a lateral hot wire feeding system. Consequently, there is no rotationally symmetrical supply of the wire material. Therefore, a constant adjustment of the hot wire feed to the torch travel direction is necessary.

The varying geometry of the welding bead depends primarily on the feeding angle of the hot wire and the entry position of the wire into arc and weld pool (leading, trailing) [31]. Up to now, it is possible to realise hot wire entry angles of approximately $50^{\circ}$ without inclination of the welding torch [32]. If more than one hot wire is used, it must be assumed that the melt pool is asymmetrical [33-36]. Variation of the weld pool geometry also influences the seam scales and thus the surface roughness [37]. In the production of rotationally symmetric components, the problem of missing direction independence can be solved by using turn-tilt tables [26, 27, 29]. TIG hot wire processes have not yet reached the productivity of GMAW high-performance processes of more than $8 \mathrm{~kg} / \mathrm{h}[18,38,39]$. The reduction of the mean melt pool temperature cannot be compensated by the joule heating due to the short preheating distance between the hot wire nozzle and the melt pool, resulting in binding defects. As a result, only small wire diameters and feeding rates can be achieved [40], resulting in low melting rates compared to other arc processes [18]. An increase of the melt pool temperature can be achieved by plasma processes, which are characterised by a significantly more concentrated heat input $[41,42]$. Based on these findings, high-performance TIG hot wire processes have already been developed with the aim of increasing melting performance and welding speed. Shinozaki et al. [43-46] and Hori et al. [47] have shown that, depending on the wire material, wire feeding rates up to approx. $9 \mathrm{~m} / \mathrm{min}$ are possible by pulsing the hot wire current. Santangelo's [48] and Henon's [38] investigations also show that drop separation and melting performance can be improved by additional mechanical oscillation of the hot wire. A further increase in the melting rate can be achieved by using two hot wire sources. Depending on the current intensity, the melting rate can almost be doubled [49]. Recent developments also show that it is possible to significantly increase the melting rate and thus also the welding speed by using two-cathode torches in combination with one or two hot wire feeders [50]. Chen's publication [51] shows that an increase in hot wire feed and thus in melting rate can be achieved by connecting the hot wire source directly to the TIG torch so that the arc attaches the hot wire. Therefore, decoupling of heat input and filler material supply is achieved. For materials with low electrical resistance, a wire preheating by an additional arc was also developed [52].

\section{Development goals}

Within the scope of the presented work, a novel GTAW hotwire system for wire-based additive manufacturing was developed, tested and evaluated, which is characterised by a high productivity as well as a direction independence at automated traversing devices to guarantee a constant bead geometry. The system allows the decoupling of melting rate and heat input through the application of a preceding preheating unit. Therefore, no contact between the wire and the melt pool is required so that the process window can be enlarged significantly. Furthermore, the process stability is increased since the arc is not deflected by the hot wire feeding. Consequently, the 
Fig. 1 (a) cathode focussed GTAW hot wire welding (b) TIG hot wire welding with indirect ohmic preheating a)

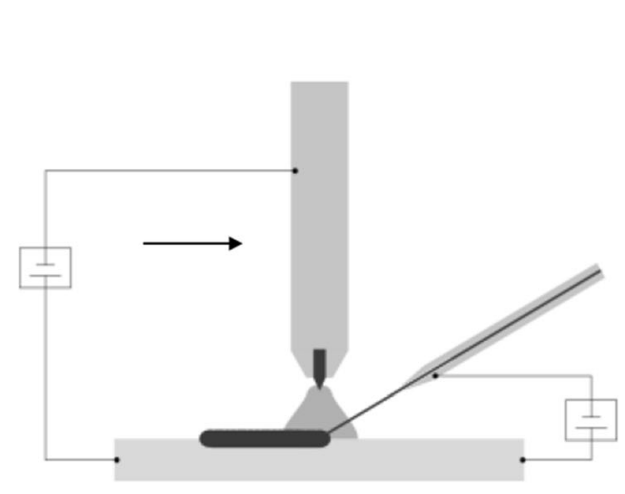

b)

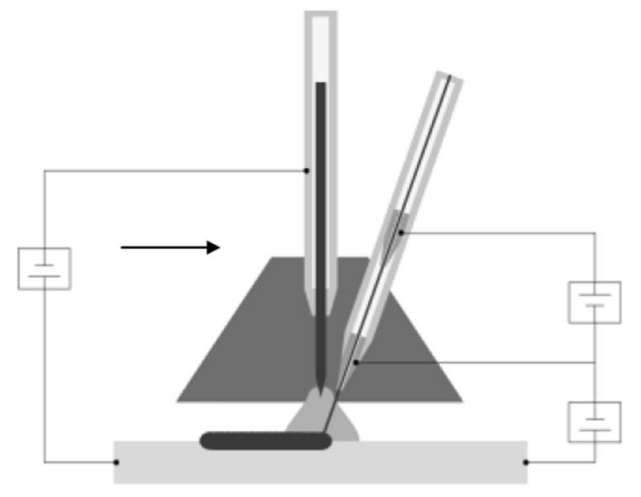

penetration of the base material is lower compared to conventional hot wire process. Additionally, small contact angles can be realised to avoid faulty connections between the individual beads.

\subsection{Realisation of torch and controlling system}

The presented torch system includes a TIG hot wire supply and a new type of process control. It consists of a TIG torch and a preheating unit, which are built into a common gas nozzle, whereby very large hot wire feeding angles of up to $70^{\circ}$, without an inclination of the TIG torch, can be achieved (see Fig. 1b). Therefore, a rotationally symmetrical heat input is guaranteed. TIG torch and hot wire feeding system have been designed in such a way that they are characterised by a high cooling performance and a very slim shaft, whereby the wire feeding angle can be increased significantly. The TIG torch has a shaft diameter of $15 \mathrm{~mm}$, whereas the hot wire system has a diameter of $20 \mathrm{~mm}$. The demonstrator has been designed in such a way that it is also possible to vary the entry position of the hot wire into the melting pool. Furthermore, the shielding gas flow can be influenced by installing different gas nozzles. The process is characterised by indirect resistive heating of the hot wire (see Fig. 1b). For this purpose, two consecutive contact points have been provided within the hot wire feeding system in order to realise an adaptable preheating current. The process is controlled by a software, which allows the adjustment of the TIG current and the hot wire current depending on the position of the welding torch on the workpiece. In addition, a further circuit for a joule preheating can be integrated between the workpiece-side contact nozzle and the substrate. The heat input into the component can be controlled independently of the selected melting rate due to the individually adjustable circuits of the TIG torch and hot wire preheating. It is also possible to vary the preheating length inside the hot wire system. The complete automation of the presented TIG hot wire process enables the realisation of a spatter-free ignition process.

\subsection{Methodical approach}

In order to prove the suitability and the potential of the developed TIG hot wire system, comparative investigations were carried out with a cathode-focused GTAW hot wire highperformance process. The test arrangement implemented for this purpose can be seen in Fig. 1a.

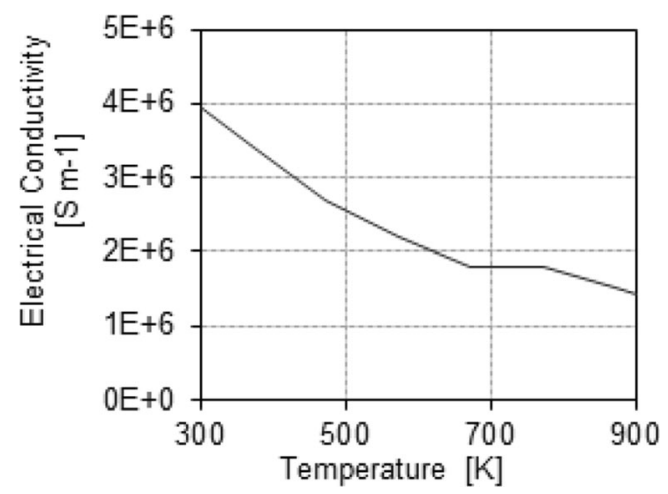

Fig. 2 Electrical conductivity as function of the temperature [55]

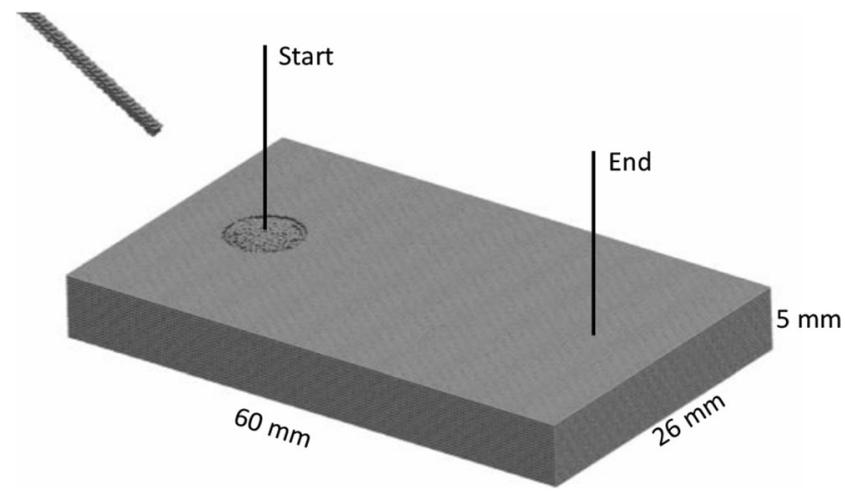

Fig. 3 Applied model geometry 


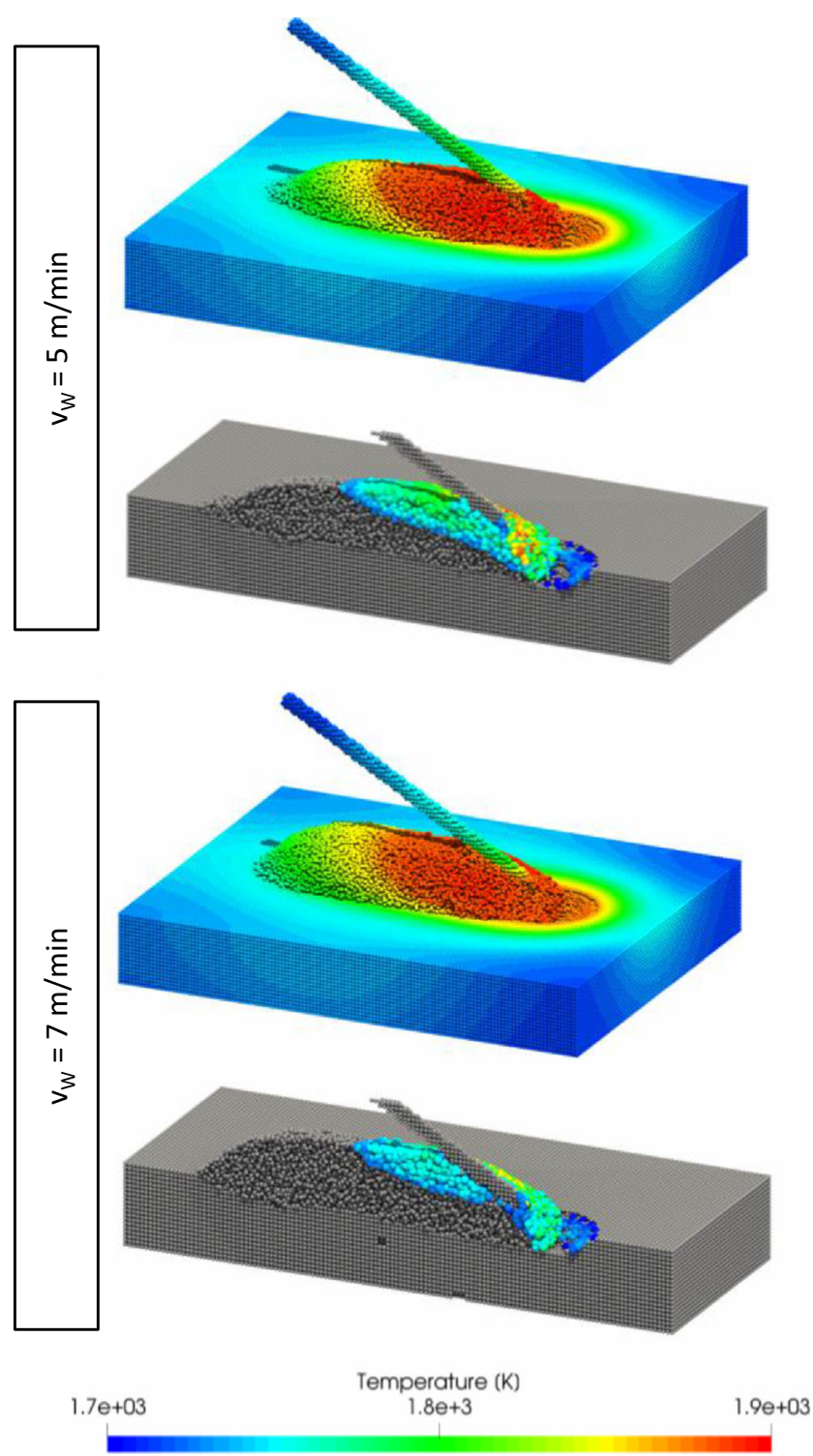

Fig. 4 Temperature distribution during cathode focussed GTAW hot wire welding

The following evaluation criteria were considered for the validation of the novel TIG hot wire process:

- Determination and comparison of the productivity of both technologies by determining the maximum wire feeding rates

- Checking the direction independence by measuring the bead geometry using 3D digital microscopy when moving the torch system in different directions, with constant position of the hot wire feeding

- Determination of the penetration and the contact angle by metallographic examinations

The following materials and geometrical relations were applied for the investigations:
- Base material: mild steel (S235JR)

- Filler wire material: mild steel (G3Si1)

- Filler wire diameter: $1.2 \mathrm{~mm}$

- Travel speed: $0.3 \mathrm{~m} / \mathrm{min}$

- Arc length: $6 \mathrm{~mm}$

Within the scope of the study, the influence of the following process parameters was examined to analyse and compare the process behaviour of the developed hot wire technology with conventional hot wire processes:

- TIG current

- Wire feeding rate

- Hot wire current

1 Preliminary studies of cathode-focussed GTAW hot wire welding using SPH method

For the further enlargement of the process boundaries of hot wire processes, the modes of failure have to be understood. In order to get an insight into the process and its behaviour, a numerical model of a cathode focussed hot wire process was developed. The model is based on the Smoothed Particle Hydrodynamics (SPH) method [53] - a lagrangian, particle based approximation for conservation equations.

The influence of the arc on the base material is approximated by imposing boundary conditions on the surface using the measured arc pressure and heat input as well as an approximated arc shear force on the weld pool surface [54]. The mathematical description of the model, including boundary conditions, has been described in detail in [54]. The model takes the weld pool flow into account including the surface tension, the Marangoni convection, the arc properties on the workpiece as well as the gravity [54]. The heat transfer considers the arc heat input, convection and thermal diffusion, the black body radiation as well as the hot wire heat input [54]. The heat input due to the hot wire current is taken into account in the solid hot wire only. As the wire diameter $d$ is known, the current density $\vec{j}$ in the wire can be calculated analytically.

$\overrightarrow{\mathrm{j}}=\frac{\pi}{4} \mathrm{~d}^{2}$

The volumetric specific heat input $\mathrm{S}_{\mathrm{q}}$ is calculated using Ohm's law with the temperature dependent electric conductivity $\sigma$ (see Fig. 2) of the filler wire material:

$S_{\mathrm{q}}=\frac{\overrightarrow{\mathrm{j}}^{2}}{\sigma}$

Figure 3 shows the applied model geometry.

The process starts at the start point and moves to the end point with a travel speed of $0.3 \mathrm{~m} / \mathrm{min}$. The total hot wire 

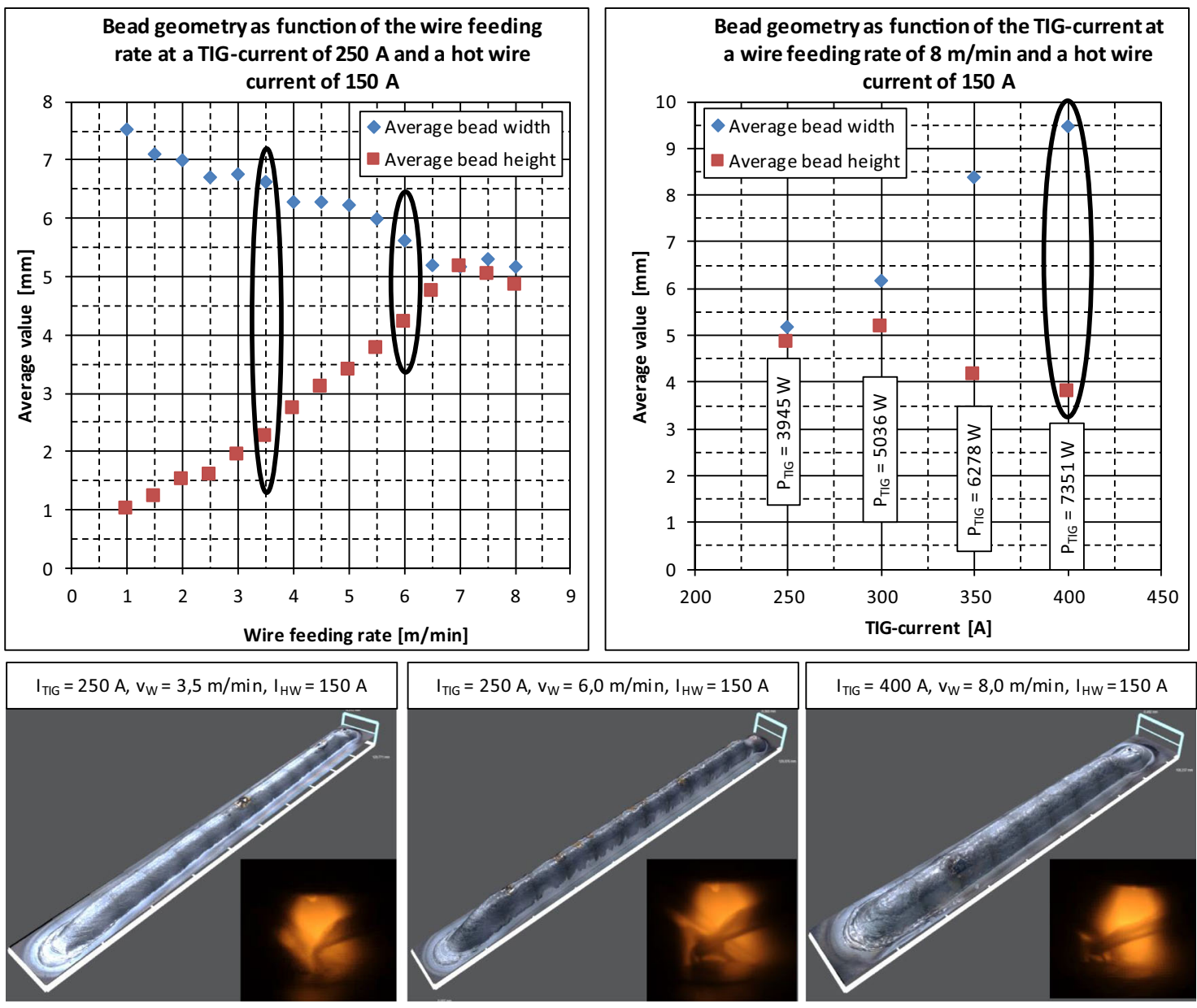

Fig. 5 Bead geometry as a function of wire feeding rate and TIG current as well as process behaviour during cathode focussed GTAW hot wire welding

speed results from the wire feeding rate in addition with the travel speed. For the calculation wire feeding rates of $5 \mathrm{~m} / \mathrm{min}$ and $7 \mathrm{~m} / \mathrm{min}$ were assumed, and a hot wire angle of $30^{\circ}$ was realised. The calculation is based on the application of a cathode focussed GTAW process with a TIG current of $250 \mathrm{~A}$ and a hot wire current of $150 \mathrm{~A}$.

Figure 4 shows the weld pool with the temperature distribution and the solid material for the two calculated wire feeding rates. In both cases, the position, at which the filler wire is molten, is located several millimetres behind the arc process. Using a wire feeding rate of $5 \mathrm{~m} / \mathrm{min}$, the wire melts on the weld pool surface. If the wire feeding rate is increased to $7 \mathrm{~m} /$ min, the wire is pushed into the weld pool and is molten inside. Therefore, it becomes obvious that high wire feeding rates require a melting position of the wire which is closer to the arc axis and thus contributes to a more direction independent process behaviour.

In Fig. 4, it can be seen that the weld pool is cooled down using high wire feeding rates due to the high amount of relatively cold filler material. This leads to smaller weld pool dimensions on the top of the solidified welding seam. In this case, the filler wire converges on the solidified welding seam, so that the possibility of a contact between wire and solid material is increased. In a real process, this would lead to a deflection or stop of the wire feed and thus irregularities can occur. It is worth mentioning that the contact of wire and solid material does not happen in the calculated case in the process area but near the melting position of the filler wire inside the weld pool. Consequently, a larger filler wire angle can improve the coaxial material transfer leading to fewer defects.

\subsection{Experimental investigations using cathode-focussed GTAW hot wire welding}

First, a process parameter study was carried out in which $100 \mathrm{~mm}$ long weld beads with leading hot wire feed arrangement were realised onto a flat sheet using a cathode focussed GTAW hot wire process. Subsequently, the beads were subjected to a $3 \mathrm{D}$ microscopic analysis, and the influence of the process parameters on the bead geometry was investigated. Figure 5 shows the bead width and height as function of the TIG current and the wire feeding rate at a hot wire current of 


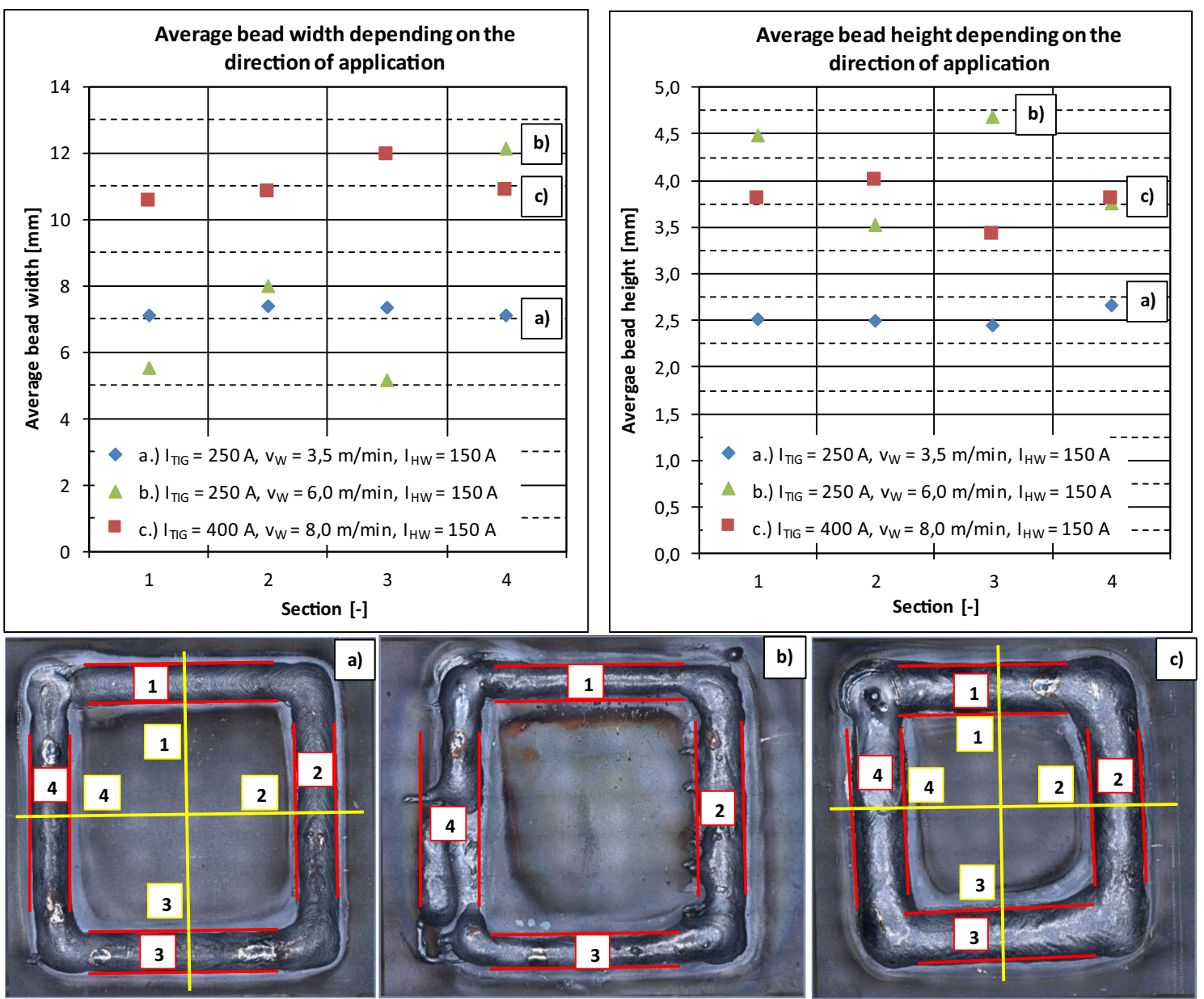

Fig. 6 Bead geometry as a function of the application direction with constant hot wire feeding during cathode focussed hot wire welding (red lines depict the measurement region of the bead geometry, yellow lines illustrate the cutting planes for the determination of penetration and contact angle)

$150 \mathrm{~A}$ and hot wire stickout of $20 \mathrm{~mm}$. The hot wire voltage was approx. $2.0 \mathrm{~V}$, resulting in a hot wire power of about $300 \mathrm{~W}$. It becomes clear that an increase of the wire feeding rate with constant TIG current leads to a decrease of the bead width with simultaneous increase of the bead height. These results correlate with existing knowledge of [39, 56, 57]. A possible explanation for this behaviour could be the higher cooling of the weld pool by the filler wire at high wire feeding rates. Due to the ohmic preheating, the filler wire has in fact a significantly higher temperature than in cold wire processes but is still significantly lower than the temperature of the existing melt pool. If the wire feeding rate is increased, more cold additional material is introduced into the melt pool, leading to a reduced mean temperature of the molten metal. As a result, there is an increase in viscosity and surface tension so that the molten material can no longer run in width but builds up in height. This results in welds with a large contact angle on the weld flanks, which are not suitable for the additive manufacturing of metallic components, as on the one hand the risk of binding defects increases. On the other hand, more beads must be realised within a layer due to the smaller bead width. In order to be able to produce flat and wide beads, the mean temperature of the melt pool must be increased directly by increasing the TIG current or indirectly by raising the hot wire temperature. In addition to increasing the hot wire current, high hot wire temperatures can also be achieved by realising a larger preheating section. However, since the preheating length correlates with the available free wire length, an increase of the preheating length leads to a reduction in process stability. Increasing the hot wire current is therefore the best way of increasing the hot wire temperature and reducing the temperature difference between the filler wire and the molten pool. However, this can lead to so much heat being introduced into the hot wire through the arc that the wire is molten before the melt pool is reached, thus breaking up the desired melting bridge. As a result, the reproducibility of the hot wire process is also significantly reduced.

Figure 5 shows the material transfer and the bead geometry achieved using 3 selected parameters. Particularly in the lower performance range, a significant constriction of the melting bridge can be recognised, since a high heat input into the filler wire occurs through the ohmic preheating and the arc process. 

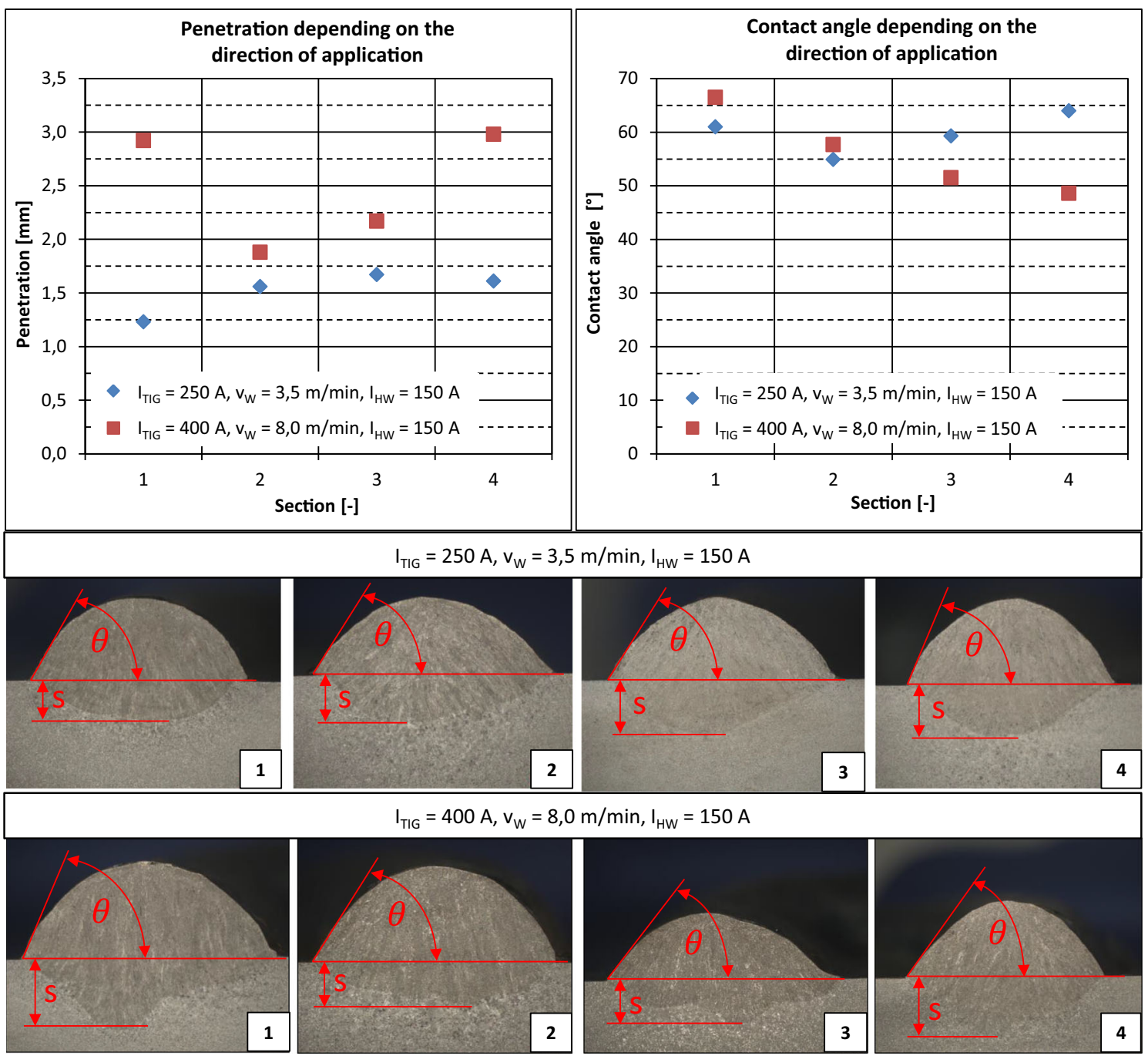

Fig. 7 Penetration and contact angle depending on the application direction with constant hot wire feeding during cathode focussed hot wire welding along the cutting planes of Fig. 6

If the heat input is further increased by adjusting the process parameters at the same wire feeding rate, the melting bridge breaks off and an irregular, material transfer appears. One way to prevent premature dripping of the hot wire is to increase the feed angle of the hot wire. However, the investigations of $\mathrm{Wu}$ show that depending on the available installation space through the application of the TIG torch and inert gas nozzle, the angle of the hot wire feeder can only be varied to a limited extent [32]. Accordingly, in the development of the hot wire system with indirect ohmic preheating, the hot wire feeding unit was integrated into the shielding gas nozzle.

Another way to increase the temperature of the molten pool is to increase the TIG current. This intensifies the transport of charged particles via the arc, whereby more energy is introduced into the component. However, this causes problems with dimensional accuracy and achieving defined mechanical-technological properties. On one hand, the higher heat input supports the development of residual stresses and distortion. On the other hand, a pronounced coarse grain growth occurs as the process proceeds, leading to differences in strength within the component, depending on the structure height [17]. As a result, longer resting times must be integrated into the build-up process in order to consider temperaturetime regimes, which finally reduce economic efficiency. In addition to the relationship between process parameters and bead geometry, the direction independence was also investigated. For this purpose, welds in form of a square were realised in order to achieve different feeding directions of the hot wire under quasi-stationary conditions. Subsequently, the bead geometry was measured using 3D digital microscopy and evaluated as function of the direction of travel. Based on this, metallographic investigations were carried out to determine the penetration and contact angle. The aim was to achieve a low penetration, to produce a low degree of melting and to obtain low contact angles to avoid undercuts.

As shown in Fig. 6, it becomes clear that by using the selected parameter sets with low and high wire feeding rates, it is possible to produce a smooth bead surface regardless of the 

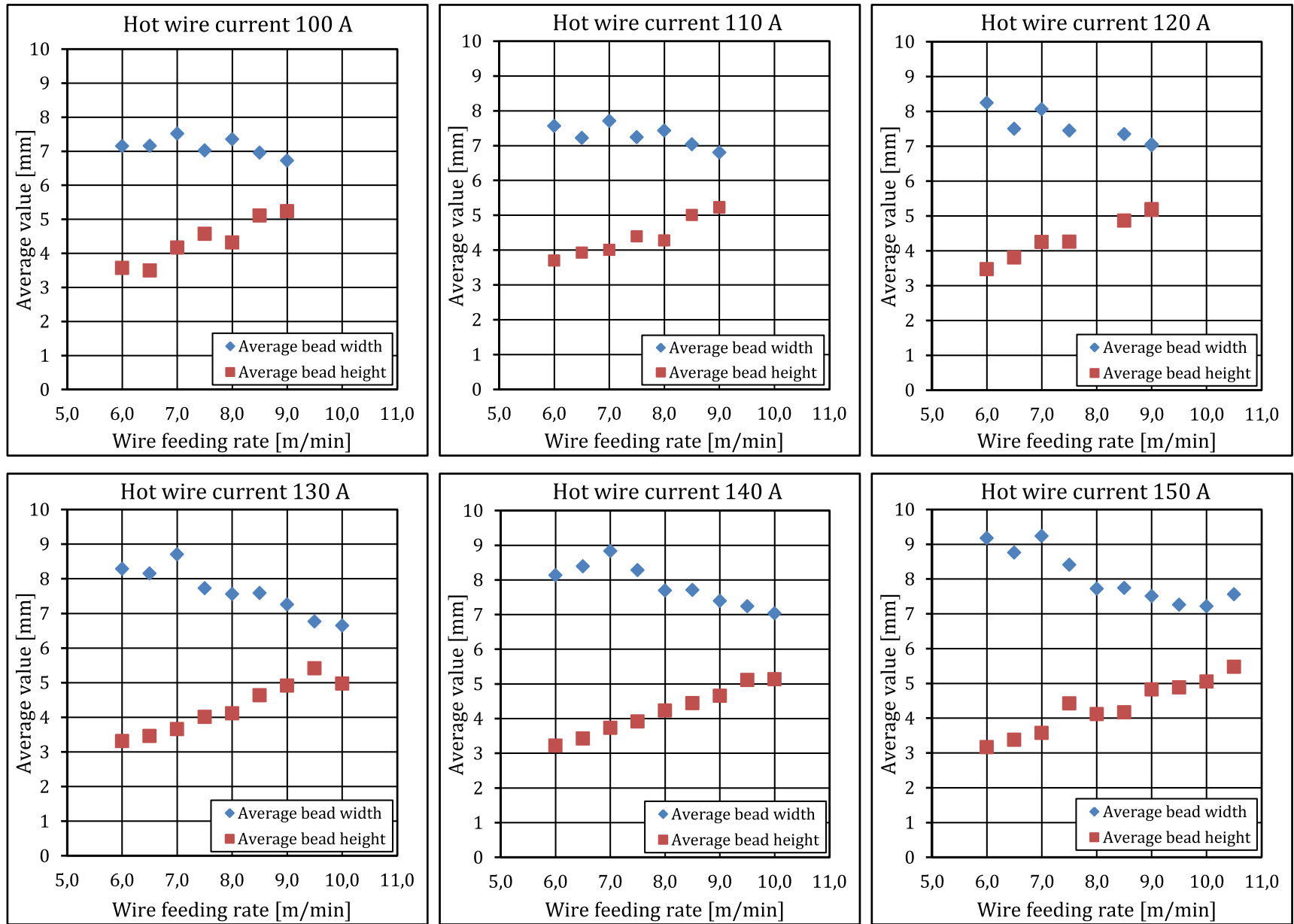

Fig. 8 Bead geometry as a function of the TIG current, hot wire current and wire feeding rate as well as external appearance of the produced seams with leading hot wire feed in travel direction during hot wire welding with indirect ohmic preheating

direction of travel. In contrast, medium wire feeding rates with $90^{\circ}$ offset of the wire feeding to the application direction lead to the collapse of the process. Since only the wire feeding rate was adjusted in the lower performance range, the cooling of the weld pool by supplying more cold additional material led to a reduction of the weld pool dimensions. As a result, the wire was molten the edge of the weld pool, resulting in irregularities. At this point, a further increase of the TIG current is necessary to produce a regular bead. Based on these results, metallographic investigations were limited to samples produced with low and high wire feeding rates $(3.5 \mathrm{~m} / \mathrm{min}$ and $8.0 \mathrm{~m} / \mathrm{min})$. Cross sections were made along the yellow marked planes (see Fig. 6), and the penetration profiles as well as the contact angles were determined. At low wire feeding rates, a uniform penetration depth can be determined regardless of the direction of application (see Fig. 7). In contrast, a clear influence of the traverse direction on the penetration can be seen at high wire feeding rates despite the TIG current was increased significantly. If the travel and wire entry axis match, a very deep and uneven penetration can be detected. If the traversing axis and wire axis are offset by $90^{\circ}$, a uniform, flat penetration profile is achieved. A possible explanation for this behaviour could be the fact that the wire does not immerse as much into the melt pool since the molten material is moved to the side by the higher arc pressure. Through the high wire feeding rate, the wire hits the bottom of the melt pool, so that the wire feed stalls for a short time and can thus be melted off. When the wire is fed from the side, the distance of the wire inside the melt pool is larger, so that melting is possible before the wire hits the bottom of the melt pool. If high wire feeding rates are aspired, the TIG current must be increased further to produce a uniform penetration profile to guarantee direction independence. However, this means that the requirements for a low heat input into the base material cannot be met adequately. In contrast to penetration, small contact angles in the range of approx. $50^{\circ}$ to approx. $65^{\circ}$ can be achieved so that a reliable bonding is possible during multi-layer deposition. This is primarily caused by the comparatively high heat input through the TIG process.

\subsection{Experimental investigations using TIG hot wire welding with indirect ohmic preheating}

To estimate the potential of the developed TIG hot wire technology, parameter studies were carried out to determine the 

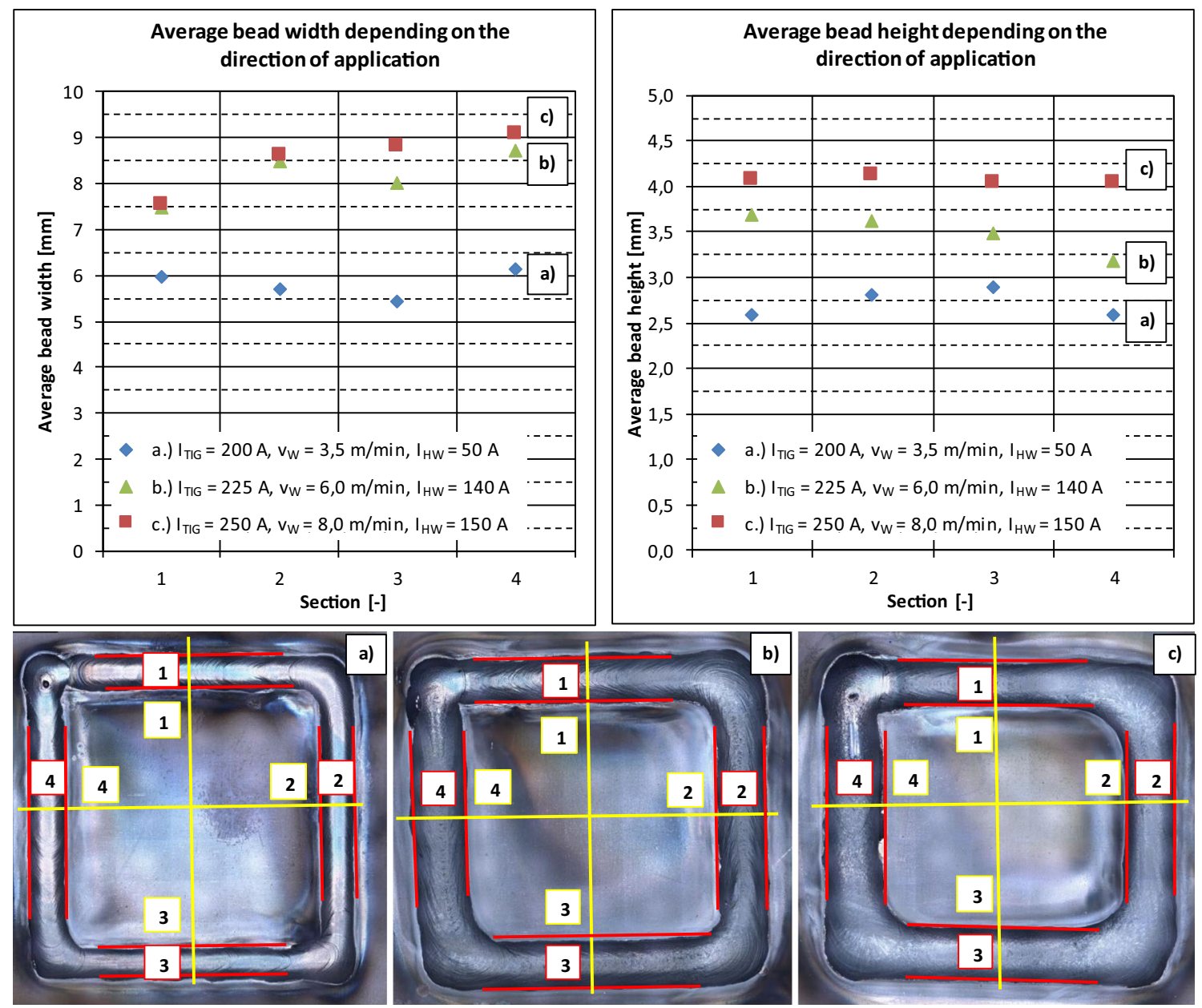

Fig. 9 Bead geometry as a function of the application direction with constant hot wire feeding during hot wire welding with indirect ohmic preheating (red lines depict the measurement region of the bead geometry,

yellow lines illustrate the cutting planes for the determination of penetration and contact angle)

process limits. Figure 8 shows the dependence of the hot wire current and the wire feeding rate on the bead geometry for a TIG current of $250 \mathrm{~A}$ using a hot wire angle of $70^{\circ}$.

The external appearances of the generated beads were compared using 3D microscopy at TIG currents of 200 A and $250 \mathrm{~A}$. The investigations show that the bead width varies only slightly even with significant changes in hot wire current and wire feeding rate. While an increase of the wire feeding rate leads to a slight decrease of the bead width, an increase of the hot wire current causes a slight increase of the bead width. At the same time, a larger bead width can be generated by increasing the TIG current. In contrast, a rise of the wire feeding rate leads to a significant increase in the height of the bead (see Fig. 8). If the hot wire current is increased, the bead height drops slightly, due to the lower viscosity and surface tension. Thus, also lower contact angles are achieved. Figure 8 illustrates this relationship. Based on the parameter studies the influence of the application direction on the bead geometry was investigated.
Figure 9 shows the bead geometry and the external appearance depending on the traversing direction. It becomes clear that the developed TIG hot wire technology makes it possible to produce very uniform welding beads regardless of the application direction, since both the bead width and the bead height are subject to minor variations. By increasing the hot wire current, an increase wire feeding rate from $6 \mathrm{~m} / \mathrm{min}$ to $8 \mathrm{~m} / \mathrm{min}$ leads to an increase of the bead width. At the same time, the bead height increases from $3.5 \mathrm{~mm}$ to $4.0 \mathrm{~mm}$. Therefore, the volume of the weld bead is increased from $22.6 \mathrm{~mm}^{2}$ to $33.2 \mathrm{~mm}^{2}$ $(+30 \%)$. In addition to the external joint analysis, cross sections along the yellow planes (see Fig. 9) were prepared for the internal joint analysis, which were used to determine the penetration profile and the contact angle (see Fig. 10).

According to Fig. 10, it becomes clear that a significant reduction of the penetration is possible using the developed TIG hot wire technology. The penetration can be reduced from approx. $1.75 \mathrm{~mm}$ to $1.15 \mathrm{~mm}(3.5 \mathrm{~m} / \mathrm{min})$ 

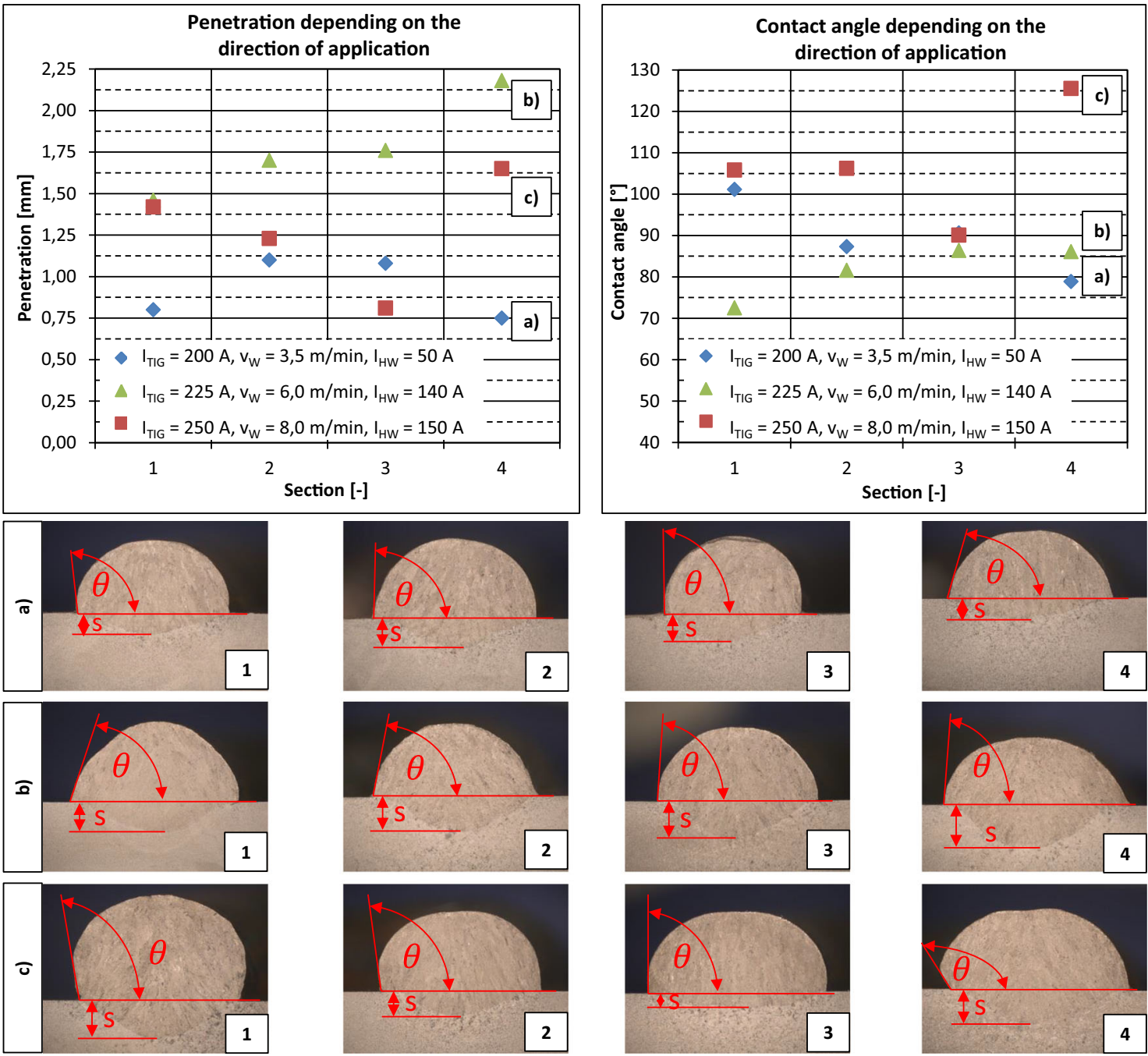

Fig. 10 Penetration and contact angle as a function of the application direction with constant hot wire feeding during hot wire welding with indirect ohmic preheating along the cutting planes of Fig. 9

and $3.00 \mathrm{~mm}$ to $1.75 \mathrm{~mm}(8.0 \mathrm{~m} / \mathrm{min})$ (see Figs. 7 and 10$)$ using the same wire feeding rate. The reason for this behaviour is the significantly reduced TIG current, so that even with high wire feeding rates only a small amount of heat is introduced into the base material. This leads to a drop in the temperature of the melt and thus to an increase in viscosity and surface tension, which produces significantly larger contact angles (see Fig. 10). Consequently the probability of bonding errors during the multi-layer deposition is increased. Due to the decoupling of material and energy input as well as the possibility to control the heat input through the individually controllable circuits, it is possible to adjust the bead geometry. The developed process also shows a high process stability and reproducibility. The parameters were chosen in a way that comparative investigations could be carried out between the conventional cathode-focused TIG hot wire process and the developed TIG hot wire process with indirect ohmic preheating. With the help of the new TIG hot wire technology, very high wire feeding rates of up to $15 \mathrm{~m} / \mathrm{min}$ can be achieved. However, from wire feeding speeds of approx. $13 \mathrm{~m} / \mathrm{min}$, feeding problems can occur so that the process stability is significantly reduced.

\subsection{Summary, conclusion and outlook}

Within the scope of the presented work, the suitability of a novel TIG hot wire system for wire and arc-based additive manufacturing was proven. It is characterised by a decoupling of wire melting rate and heat input. Therefore, even at high melting rates, less heat can be introduced into the component, which reduces residual stresses and distortion. The aim was to improve the quality of additively manufactured component structures with regard to dimensional accuracy. This is of fundamental importance in order to be able to produce complex components economically in small quantities and consequently 
to support the transfer of arc-based additive production into industrial practice. The GTAW hot wire technology is characterised by the following characteristics:

- High productivity through achievable wire feeding rates of up to $15 \mathrm{~m} / \mathrm{min}$

- Direction independence through high wire feeding angles up to $75^{\circ}$ and hot wire feeding inside the gas nozzle

- Low penetration of the component but high contact angles through very low heat input

The findings form the basis for further investigations regarding the wire feeding angle and the positioning of TIGtorch and hot wire unit. Therefore, the process tolerance and reproducibility will be determined. In addition, the mechanical-technological properties will be determined and further research studies using high-alloyed steels as well as nonferrous materials and materials with high thermal conductivity will be carried out. Finally, it is planned to develop a prototype for welding under industrial conditions.

Funding Information Open Access funding provided by Projekt DEAL.

Open Access This article is licensed under a Creative Commons Attribution 4.0 International License, which permits use, sharing, adaptation, distribution and reproduction in any medium or format, as long as you give appropriate credit to the original author(s) and the source, provide a link to the Creative Commons licence, and indicate if changes were made. The images or other third party material in this article are included in the article's Creative Commons licence, unless indicated otherwise in a credit line to the material. If material is not included in the article's Creative Commons licence and your intended use is not permitted by statutory regulation or exceeds the permitted use, you will need to obtain permission directly from the copyright holder. To view a copy of this licence, visit http://creativecommons.org/licenses/by/4.0/.

\section{References}

1. Liu, L.; Zhuang, Z.; Liu, F.; Zhu, M.: Additive manufacturing of steel-bronze bimetal by shaped metal deposition: interface characteristics and tensile properties. In: The International Journal of Advanced Manufacturing Technology Vol 69 (2013), 9-12, pp. 2131-2137

2. Ding, D.; Pan, Z.; Cuiuri, D.; Li, H.: Wire-feed additive manufacturing of metal components: technologies, developments and future interests. In: The International Journal of Advanced Manufacturing Technology Vol 81 (2015), 1-4, pp. 465-481

3. Guo, N.; Leu, M. C.: Additive manufacturing: technology, applications and research needs. In: Frontiers of Mechanical Engineering Vol 8 (2013), 3, pp. 215-243

4. Petrovic V, Haro JV, Jordá O, Delgado J, Blasco JR, Portolés L (2010) Additive Layer Manufacturing: state of the art in industrial applications through case studies. In: International Journal of Production Research, p 1

5. Bandari YK, Williams SW, Ding J, Martina F Additive manufacture of large structures: robotic or CNC systems? pp. 9
6. Kazanas, P.; Deherkar, P.; Almeida, P.; Lockett, H.; Williams, S. W.: Fabrication of geometrical features using wire and arc additive manufacture. In: Proceedings of the Institution of Mechanical Engineers, Part B: Journal of Engineering Manufacture Vol. 226 (2012), 6, pp. 1042-1051

7. Antonysamy AA (2012) Microstructure, texture and mechanical property evolution during additive manufacturing of Ti6Al4V alloy for aerospace applications, Phd- thesis. The University of Manchester, Manchester

8. Ding $\mathrm{J}$ Thermo-mechanical analysis of wire and arc additive manufacturing process (2012)

9. Schroepfer, D.; Kromm, A.; Kannengiesser, T.: Engineering approach to assess residual stresses in welded components In: Welding in the World, Vol. 61 (2017), 1, pp. 91-106

10. Martina F, Colegrove PA, Williams SW Microstructure of interpass rolled wire + arc additive manufacturing Ti-6Al-4V components (2015)

11. Martina F, Roy M, Colegrove P, Williams SW Residual stress reduction in high pressure interpass rolled wire and arc additive manufacturing Ti-6Al-4V components, pp. 6

12. Kah, P.; Suoranta, R.; Martikainen, J.: Advanced gas metal arc welding processes. In: The International Journal of Advanced Manufacturing Technology Vol 67 (2013), 1-4, pp. 655-674

13. Williams, S. W.; Martina, F.; Addison, A. C.; Ding, J.; Pardal, G.; Colegrove, P.: Wire + arc additive manufacturing. In: Materials Science and Technology Vol 32 (2016), 7, pp. 641-647

14. Almeida P, Williams SW (2010) Innovative process model of Ti$6 \mathrm{Al}-4 \mathrm{~V}$ additive layer manufacturing using cold metal transfer (CMT). In: 21st annual international solid freeform fabrication symposium - an additive manufacturing conference, SFF, vol 2010, pp 25-36

15. Posch, G.; Chladil, K.; Chladil, H.: Material properties of CMTmetal additive manufactured duplex stainless steel blade-like geometries In: Welding in the World, Vol. 61 (2017), 5, pp. 873-882

16. Bergmann JP, Frisch W, Günther K (2013), Nr. Heft 9) Aufmischungsarmes, endkonturnahes Auftragschweißen hartstoffverstärkter Fe-Hartpanzerungen mittels geregelter, energiereduzierter MSGKurzlichtbogentechnik. In: Schweißen und Schneiden Bd. 63, pp 602-607

17. Ali Y, Günther K, Henckell P, Bergmann JP Additive Fertigung von 3D-Verbundstrukturen mittels MSG-Schweißen. In: DVS-Berichte Bd., vol 327, pp 75-79

18. Aichele G, Spreitz W Kostenrechnen und Kostensenken in der Schweißtechnik - Handbuch zum Kalkulieren, wirtschaftlichen Konstruieren und Fertigen, 2001, pp. 141

19. Ding, J.; Colegrove, P.; Mehnen, J.; Ganguly, S.; Sequeira Almeida, P. M.; Wang, F.; Williams, S. W.: Thermo-mechanical analysis of Wire and arc additive layer manufacturing process on large multilayer parts In: Computational Materials Science, Vol. 50 (2011), 12, pp. 3315-3322

20. Wang, F.; Williams, S. W.; Colegrove, P.; Antonysamy, A. A.: Microstructure and mechanical properties of wire and arc additive manufactured Ti-6Al-4V. In: Metallurgical and Materials Transactions A, Vol. 44 (2013), 2, pp. 968-977

21. Hori K, Myoga T, Shinomiya M, Watanabe E, Kusano K, Takuwa T, Hafuri M Semi-automatic hot wire tig welding equipment, United States patent 4801781

22. Bai, J. Y.; Fan, C. L.; Lin, S.; Yang, C. L.; Dong, B. L.: Effects of thermal cycles on microstructure evolution of 2219-Al during GTAadditive manufacturing. In: The International Journal of Advanced Manufacturing Technology, Vol. 87 (2016), 9-12, pp. 2615-2623

23. Yilmaz, O.; Ugla, A. A.: Microstructure characterization of SS308LSi components manufactured by GTAW-based additive manufacturing: shaped metal deposition using pulsed current arc. In: The International Journal of Advanced Manufacturing Technology, Vol. 89 (2017), 1-4, pp. 13-25 
24. Jandric, Z.; Labudovic, M.; Kovacevic, R.: Effect of heat sink on microstructure of three-dimensional parts built by welding-based deposition In: International Journal of Machine Tools and Manufacture, Vol. 44 (2004), 7, pp. 785-796

25. Ma Y (2015) Fabrication of gamma titanium aluminide alloys by gas tungsten arc welding-based additive layer manufacturing. In: University of Wollongong Thesis Collection, vol 1954-2016

26. Baufeld, B.; Biest, V.D.O.: Mechanical properties of Ti-6Al-4V specimens produced by shaped metal deposition. In: Science and Technology of Advanced Materials, Vol. 10 (2009), 1, pp. 015008

27. Baufeld B, Biest VDO, Gault R (2010) Additive manufacturing of Ti-6Al-4V components by shaped metal deposition: microstructure and mechanical properties. In: Materials \& Design, vol 31, pp S106-S111

28. Baufeld, B.; Biest, V.D.O.; Gault, R.; Ridgway, K.: Manufacturing Ti-6Al-4V components by shaped metal deposition: microstructure and mechanical properties. In: IOP Conference Series: Materials Science and Engineering, Vol. 26 (2011), 1, pp. 012001

29. Baufeld, B: Effect of deposition parameters on mechanical properties of shaped metal deposition parts. In: Proceedings of the Institution of Mechanical Engineers, Part B: Journal of Engineering Manufacture, Vol. 226 (2012), 1, pp. 126-136

30. Baufeld, B.: Mechanical properties of INCONEL 718 parts manufactured by shaped metal deposition (SMD). In: Journal of Materials Engineering and Performance, Vol. 21 (2012), 7, pp. $1416-1421$

31. Geng H, Li J, Xiong J, Lin X, Zhang F (2017) Optimization of wire feed for GTAW based additive manufacturing. In: Journal of Materials Processing Technology, vol 243, pp 40-47

32. Wu, Q.; Lu, J.; Liu, C.; Shi, X.; Ma, Q.; Tang, S.; Fan, H.; Ma, S.: Obtaining uniform deposition with variable wire feeding direction during wire-feed additive manufacturing In: Materials and Manufacturing Processes, Vol. 32 (2017), 16, pp. 1881-1886

33. Ma, Y.; Cuiuri, D.; Hoye, N.; Li, H.; Pan, Z.: Characterization of insitu alloyed and additively manufactured titanium aluminides In: Metallurgical and Materials Transactions B, Vol. 45 (2014), 6, pp. 2299-2303

34. Shen C, Pan Z, Cuiuri D, Dong B, Li H (2016) In-depth study of the mechanical properties for $\mathrm{Fe} 3 \mathrm{Al}$ based iron aluminide fabricated using the wire-arc additive manufacturing process. In: Materials Science and Engineering: A, vol 669, pp 118-126

35. Shen, C.; Pan, Z.; Cuiuri, D.; Ding, D.; Li, H.: Influences of deposition current and interpass temperature to the Fe-Al-based iron aluminide fabricated using wire-arc additive manufacturing process In: The International Journal of Advanced Manufacturing Technology, Vol. 88 (2017), 5-8, pp. 2009-2018

36. Dong, B.; Pan, Z.; Shen, C.; Ma, Y.; Li, H.: Fabrication of CopperRich $\mathrm{Cu}-\mathrm{Al}$ Alloy Using the wire-arc additive manufacturing process In: Metallurgical and Materials Transactions B, Vol. 48 (2017), 6, pp. 3143-3151

37. Syed, W. U. H.; Li, L.: Effects of wire feeding direction and location in multiple layer diode laser direct metal deposition. In: Applied Surface Science, 4th International Conference on Photo-Excited Processes and Applications, Vol. 248 (2005), 1, pp. 518-524

38. Henon KB Advances in automatic hot wire GTAW (TIG) welding | arc machines, Inc., Case Study, Pacoima, 2015

39. Padmanaban M. R. A.; Neelakandan, B.; Kandasamy, D.: A Study on process characteristics and performance of hot wire gas tungsten arc welding process for high temperature materials In: Materials Research, Vol. 20 (2017), 1, pp. 76-87

40. Ueguri, S.; Tabata, Y.; Shimizu, T.; Mizuno, T.: Control of deposition rates in hot wire TIG welding In: Welding International, Vol. 1 (1987), 8, pp. 736-742

41. Martina, F.; Mehnen, J.; Williams, S. W.; Colegrove, P.; Wang, F.: Investigation of the benefits of plasma deposition for the additive layer manufacture of Ti-6Al-4V. In: Journal of Materials Processing Technology, Vol. 212 (2012), 6, pp. 1377-1386

42. Jhavar, S.; Jain, N. K.; Paul, C. P.: Development of micro-plasma transferred arc ( $\mu$-PTA) wire deposition process for additive layer manufacturing applications. In: Journal of Materials Processing Technology, Vol. 214 (2014), 5, pp. 1102-1110

43. Shinozaki K, Yamamoto M, Nagashima T, Sakamoto M, Nagamitsu Y In situ observation of wire melting -study on high speed welding with hot wire TIG welding methods using pulsed current to heat filler wire (Report2) 2006

44. Shinozaki K, Motomichi Y, Mitsuhata K, Nagashima T, Tatsunori $\mathrm{K}$, Arashin H Development of ultra-highspeed GTA welding process using pulse-heated hot-wire. Preprints of the National Meeting of the Japan Welding, 2008

45. Shinozaki, K. ; Yamamoto, M. ; Nagamitsu, Y. ; Uchida, T. ; Mitsuhata, K. ; Nagashima, T. ; Kanazawa, T. ; Arashin, H.: Melting phenomenon during ultra-high-speed GTA Welding Method using pulse-heated hot-wire. In: Querly journal of the japan welding society, Vol. 27 (2009), 2, pp. 22s-26s

46. Shinozaki, K.; Yamamoto, M.; Mitsuhata, K.; Nagashima, T.; Kanazawa, T.; Arashin, H.: Bead formation and wire temperature distribution during ultra high speed GTA welding using pulseheated hot-wire In: Welding in the World, Vol. 55 (2011), 3-4, pp. $12-18$

47. Hori, K.; Watanabe, H. ; Myoga, T. ; Kusano, K.: Development of hot wire TIG welding methods using pulsed current to heat filler wire - research on pulse heated hot wire TIG welding processes In: Welding International, Vol. 18 (2004), 6, pp. 456-468

48. Santangelo M, Silwal B, Purdy A Vibration Assisted Robotic HotWire Gas Tungsten Arc Welding (GTAW) for Additive Manufacturing of Large Metallic Parts (2016), pp. 1548-1556

49. Zheng S, Kuo M, Dayou P (1999) Twin wire gas tungsten arc cladding. In: SIMTech Technical Report (PT/99/004/JT)

50. Egerland, S.; Zimmer, J.; Brunmaier, R.; Nussbaumer, R.; Posch, G.; Rutzinger, B.: Advanced gas tungsten arc weld surfacing current status and application. In: Soldagem, Inspeção, Vol. 20 (2015), 3, pp. 300-314

51. Chen J, Lu Y, Li XR, Zhang YM (2012) Gas tungsten arc welding using an arcing wire. In: Welding Journal, vol 91, pp 261s-269s

52. Lv, S. X.; Tian, X. B.; Wang, H. T.; Yang, S. Q.: Arc heating hot wire assisted arc welding technique for low resistance welding wire In: Science and Technology of Welding and Joining, Vol. 12 (2007), 5, S. 431-435

53. Monaghan, J. J.: Smoothed particle hydrodynamics In: Annual Review of Astronomy and Astrophysics, Vol. 30 (1992), 1, pp. 543-574

54. Trautmann M, Hertel M, Füssel U (2017) Numerical simulation of TIG weld pool dynamics using smoothed particle hydrodynamics. In: International Journal of Heat and Mass Transfer, vol 115, pp 842-853

55. Richter F Die physikalischen Eigenschaften der Stähle - Das 100 Stähle Programm Teil I: Tafeln und Bilder The Physical Properties of Steels - The 100 Steels Programme Part I: Tables and Figures, Mülheim a.d. Ruhr, 1991

56. Olivares, E. A. G., Diaz, V. M. V.: Study of the hot-wire TIG process with AISI-316L filler material, analysing the effect of magnetic arc blow on the dilution of the weld bead. In: Welding International, Vol. 32, 2, pp. 139-148, 2018

57. Shah, P., Agrawal, C.: A review on twin tungsten inert gas welding process accompanied by hot wire pulsed power source. In: Journal of Welding and Joining, Vol. 37, 2, pp. 139-148, 2019

Publisher's note Springer Nature remains neutral with regard to jurisdictional claims in published maps and institutional affiliations. 